\title{
Prostate-Specific Antigen Testing Initiation and Shared Decision-Making: Findings from the 2000 and 2015 National Health Interview Surveys
}

Jun Li, MD, PhD, Helen Ding, MD, MSPH, Thomas B. Richards, MD,

Iman Martin, PhD, MPH, Sarab Kobrin, PhD, MPH, and Pamela M. Marcus, PhD

Purposes: Despite recommendations against prostate cancer screening with prostate-specific antigen (PSA) tests, about one-fourth of men age $\geq \mathbf{4 0}$ years received PSA tests in 2015 . This study aimed to answer 3 questions for men who had a PSA test in the past year: (1) What percentage of these men received the test first suggested by physicians? (2) What factors were associated with physician-initiated PSA testing (PIPT) versus patient/someone else-initiated testing? (3) What percentage of patients ever had shared decision-making when tests were initiated by physicians?

Methods: We analyzed the 2000 and 2015 National Health Interview Survey data. We calculated agestandardized prevalence of PIPT for both years. For 2015, we used logistic regression to calculate adjusted prevalence ratios for PIPT. We also calculated the prevalence of ever discussing both advantages and disadvantages.

Results: The age-standardized prevalence of PIPT was significantly higher in 2015 (84.9\%) than in 2000 (72.3\%). In 2015, nearly $90 \%$ of PSA screenings for men aged $\geq 70$ years were suggested by physicians. PIPT was positively associated with 2 or more comorbid conditions and number of patient visits to the doctor. Less than one-third of men reported they had ever participated in a discussion of advantages and disadvantages of PSA testing.

Conclusions: The majority of men who had PSA testing in the past year reported that their physicians were the first to suggest testing, including men aged $\geq 70$ years. Our study also points to the challenges and needs in conducting shared decision-making before PSA testing in clinical practice. ( $\mathrm{J}$ Am Board Fam Med 2018;31:658-662.)

Keywords: Decision Making, Early Detection of Cancer, Logistic Regression, Prevalence, Prostate Cancer, ProstateSpecific Antigen

Despite recommendations against prostate cancer screening with prostate-specific antigen (PSA) tests, approximately one-fourth of men age $\geq 40$ years received PSA tests in $2015 .^{1}$ Many organizations, including the US Preventive Task Force (USPSTF), recommend that health care providers

This article was externally peer reviewed.

Submitted 27 November 2017; revised 1 February 2018; accepted 13 February 2018.

From Division of Cancer Prevention and Control, National Center for Chronic Disease Prevention and Health Promotion, CDC, Atlanta, GA (JL, TBR); DB Consulting Group INC, Silver spring, MD (HD); Division of Cancer Prevention, National Cancer Institute, Bethesda, (IM); Division of Cancer Control and Population Sciences, National Cancer Institute, Bethesda, (SK, PMM).

Funding: none.

Conflict of interest: none declared. and their patients use shared decision-making (SDM), including discussion of benefits and harms of the test, before ordering it. ${ }^{1}$ This study aimed to answer 3 questions for men who had a PSA test in the past year: (1) What percentage of these men received the test first suggested by physicians? (2) What factors were associated with physician-

Corresponding author: Jun Li, MD, PhD, Epidemiology and Applied Research Branch, Division of Cancer Prevention and Control, Centers for Disease Control and Prevention, 4770 Buford Hwy, Mail Stop F-76, Atlanta, GA 30341 (E-mail: ffa2@cdc.gov).

Disclosure: The findings and conclusions in this report are those of the authors and do not necessarily represent the official position of the Centers for Disease Control and Prevention and National Cancer Institute. 
Table 1. Age-Standardized* Prevalence of Physician-Initiated Prostate-Specific Antigen Testing by Sociodemographic and Screening-Related Factors Among Men Aged 40 Years and Older Who Had the Test in the Past Year, National Health Interview Survey, 2000 and 2015

\begin{tabular}{|c|c|c|c|c|c|c|c|c|}
\hline \multirow[b]{3}{*}{ Total } & \multicolumn{4}{|c|}{2000} & \multicolumn{3}{|c|}{2015} & \multirow{3}{*}{$\frac{\frac{P \text { value }^{\ddagger}}{(2015 \text { vs } 2000)}}{<.01}$} \\
\hline & \multirow{2}{*}{$\frac{\mathrm{N}^{\dagger}}{1642}$} & \multirow{2}{*}{$\begin{array}{c}\% \\
72.3\end{array}$} & \multicolumn{2}{|c|}{$95 \% \mathrm{CI}$} & \multirow{2}{*}{$\frac{N^{\dagger}}{2018}$} & \multirow{2}{*}{$\begin{array}{c}\% \\
84.9\end{array}$} & \multirow{2}{*}{$\frac{95 \% \mathrm{CI}}{82.0-87.4}$} & \\
\hline & & & 69.0 & 75.4 & & & & \\
\hline \multicolumn{9}{|l|}{ Age, crude estimates } \\
\hline 40 to 54 years & 462 & 66.1 & 60.7 & 71.1 & 380 & 83.2 & $78.2-87.2$ & $<.01$ \\
\hline 55 to 69 years & 707 & 76.2 & 72.4 & 79.7 & 1029 & 85.5 & $82.5-88.1$ & $<.01$ \\
\hline $70+$ years & 473 & 85.4 & 81.2 & 88.7 & 609 & 89.3 & $85.2-92.4$ & .13 \\
\hline \multicolumn{9}{|l|}{ Race } \\
\hline White & 1375 & 72.9 & 69.3 & 76.2 & 1692 & 84.6 & $81.4-87.3$ & $<.01$ \\
\hline Black & 189 & 72.7 & 64.3 & 79.7 & 243 & 87.3 & $79.0-92.7$ & $<.01$ \\
\hline Others & 78 & $71.0^{\S}$ & 58.6 & 80.9 & 83 & 87.1 & $75.7-93.6$ & .03 \\
\hline \multicolumn{9}{|l|}{ Ethnicity } \\
\hline Hispanic & 132 & 60.9 & 51.0 & 70.0 & 140 & 85.2 & $75.3-91.5$ & $<.01$ \\
\hline Non-Hispanic & 1510 & 73.0 & 69.5 & 76.2 & 1878 & 84.9 & $81.9-87.5$ & $<.01$ \\
\hline \multicolumn{9}{|l|}{ Region } \\
\hline Northeast & 325 & 76.8 & 71.0 & 81.8 & 346 & 81.7 & $72.6-88.3$ & .31 \\
\hline Midwest & 379 & 67.5 & 61.4 & 73.1 & 441 & 86.3 & $79.2-91.2$ & $<.01$ \\
\hline West & 634 & 74.0 & 67.6 & 79.4 & 745 & 86.0 & $82.1-89.2$ & $<.01$ \\
\hline South & 304 & 70.5 & 63.0 & 77.0 & 486 & 83.8 & $76.6-89.1$ & .01 \\
\hline \multicolumn{9}{|l|}{ Born in United States } \\
\hline Yes & 1489 & 73.1 & 69.6 & 76.4 & 1792 & 85.7 & $82.6-88.3$ & $<.01$ \\
\hline No & 146 & 62.1 & 53.1 & 70.2 & 224 & 81.7 & $73.9-87.5$ & $<.01$ \\
\hline \multicolumn{9}{|l|}{ Education } \\
\hline Less than high school & 273 & 63.0 & 53.9 & 71.3 & 184 & $88.8^{\S}$ & $74.2-95.6$ & $<.01$ \\
\hline High school graduate & 431 & 74.7 & 67.6 & 80.6 & 483 & 83.4 & $75.3-89.2$ & .07 \\
\hline Some college & 416 & 73.6 & 68.1 & 78.5 & 554 & 85.7 & $80.1-89.9$ & $<.01$ \\
\hline College graduate & 510 & 69.3 & 64.1 & 74.1 & 794 & 84.3 & $79.9-88.0$ & $<.01$ \\
\hline \multicolumn{9}{|l|}{ Marital status } \\
\hline Married or living with partner & 1155 & 71.6 & 67.9 & 75.0 & 1339 & 85.2 & $82.0-88.0$ & $<.01$ \\
\hline Widowed, divorced, or separated & 357 & 74.5 & 66.8 & 80.9 & 503 & 81.9 & $74.3-87.7$ & .13 \\
\hline Never married & 126 & 75.9 & 66.4 & 83.3 & 174 & 81.1 & $70.1-88.7$ & .41 \\
\hline \multicolumn{9}{|l|}{ Currently employed } \\
\hline No & 822 & 79.2 & 71.4 & 85.3 & 1067 & 90.1 & $85.9-93.2$ & .01 \\
\hline Yes & 820 & 69.7 & 65.4 & 73.7 & 949 & 84.0 & $80.0-87.3$ & $<.01$ \\
\hline \multicolumn{9}{|l|}{ Poverty threshold, \% } \\
\hline$<200$ & 339 & 80.0 & 70.1 & 87.2 & 378 & 87.8 & $81.8-92.0$ & .12 \\
\hline 200 to 299 & 283 & 68.2 & 60.5 & 75.1 & 308 & 88.5 & $79.5-93.8$ & $<.01$ \\
\hline 300 to 399 & 219 & 74.8 & 66.9 & 81.3 & 257 & 82.3 & $72.3-89.2$ & .19 \\
\hline 400 to 499 & 189 & 70.8 & 62.9 & 77.7 & 229 & 82.4 & $73.3-88.8$ & .03 \\
\hline 500 and more & 612 & 69.8 & 64.8 & 74.4 & 846 & 84.5 & $80.0-88.1$ & $<.01$ \\
\hline \multicolumn{9}{|l|}{ Usual source of medical care } \\
\hline Yes & 1604 & 73.0 & 69.7 & 76.1 & 1971 & 85.0 & $82.0-87.5$ & $<.01$ \\
\hline No & 38 & $41.9^{\S}$ & 27.4 & 58.0 & 46 & $81.8^{\S}$ & $63.3-92.1$ & $<.01$ \\
\hline \multicolumn{9}{|l|}{ Health insurance } \\
\hline Uninsured/Medicaid & 106 & $82.2^{\S}$ & 68.7 & 90.7 & 144 & 83.6 & $73.1-90.5$ & .85 \\
\hline Private/Military/Other & 1531 & 71.9 & 68.5 & 75.1 & 1869 & 85.0 & $82.0-87.5$ & $<.01$ \\
\hline
\end{tabular}


Table 1. Continued

\begin{tabular}{|c|c|c|c|c|c|c|c|c|}
\hline & \multicolumn{4}{|c|}{2000} & \multicolumn{3}{|c|}{2015} & \multirow{2}{*}{$\frac{P \text { value }^{\ddagger}}{(2015 \text { vs } 2000)}$} \\
\hline & $\mathbf{N}^{\dagger}$ & $\%$ & $95 \%$ & CI & $\mathbf{N}^{\dagger}$ & $\%$ & $95 \%$ CI & \\
\hline \multicolumn{9}{|c|}{ Number of doctor visits in the past year } \\
\hline 1 & 242 & 71.3 & 63.8 & 77.7 & 298 & 73.1 & $64.7-80.1$ & .73 \\
\hline 2 & 522 & 67.1 & 61.3 & 72.4 & 681 & 86.4 & $81.9-89.9$ & $<.01$ \\
\hline $3+$ & 878 & 76.3 & 72.1 & 80.1 & 1039 & 89.4 & $85.8-92.2$ & $<.01$ \\
\hline \multicolumn{9}{|c|}{ Family history of prostate cancer } \\
\hline No & 1517 & 73.2 & 69.8 & 76.3 & 1806 & 87.1 & $84.6-89.2$ & $<.01$ \\
\hline Yes & 125 & 64.8 & 55.7 & 72.9 & 212 & $68.6^{\S}$ & $56.9-78.2$ & .59 \\
\hline \multicolumn{9}{|c|}{ Cancer, excluding prostate and nonmelanoma skin } \\
\hline No & 1534 & 72.2 & 69.0 & 75.2 & 1820 & 85.0 & $82.0-87.5$ & $<.01$ \\
\hline Yes & 106 & $75.0^{\S}$ & 58.8 & 86.3 & 197 & $83.2^{\S}$ & $67.1-92.3$ & .39 \\
\hline \multicolumn{9}{|l|}{ Comorbidity $\|$} \\
\hline None & 1326 & 71.4 & 68.1 & 74.5 & 1608 & 84.9 & $81.8-87.6$ & $<.01$ \\
\hline 1 disease & 279 & 79.7 & 70.7 & 86.5 & 339 & $81.5^{\S}$ & $67.0-90.5$ & .80 \\
\hline $2+$ diseases & 36 & $82.9^{\S}$ & 67.9 & 91.8 & 71 & 97.2 & $91.1-99.2$ & .02 \\
\hline \multicolumn{9}{|l|}{ Reported health status } \\
\hline Excellent/very good & 900 & 72.0 & 68.0 & 75.7 & 1093 & 83.8 & $79.8-87.1$ & $<.01$ \\
\hline Good/fair or poor & 741 & 72.1 & 66.8 & 76.8 & 925 & 86.5 & $82.8-89.5$ & $<.01$ \\
\hline \multicolumn{9}{|c|}{ Had colorectal cancer screening } \\
\hline Yes & 805 & 72.6 & 68.7 & 76.3 & 426 & 83.4 & $78.3-87.5$ & $<.01$ \\
\hline No & 824 & 70.7 & 65.3 & 75.6 & 1588 & 87.7 & $84.1-90.6$ & $<.01$ \\
\hline
\end{tabular}

*Results for all variables except age were age standardized to the age distribution of the 2000 standard population.

${ }^{\dagger}$ Number may differ from 1646 for 2000 National Health Interview Survey and 2024 for 2015 NHIS because of “don't know," refused, or missing responses.

${ }^{\ddagger} P$ value is calculated by $t$ test from the contrast statement of PROC DESCRIPT procedure.

${ }^{\S}$ Estimates may not be reliable as the confidence interval half width $\geq 10$.

|Number of the following comorbidities (none, 1, 2, and more diseases): hypertension, stroke, diabetes, chronic heart, kidney, liver, and lung diseases.

CI, confidential interval.

initiated PSA testing (PIPT) versus patient/ someone else-initiated testing? (3) What percentage of patients ever had SDM when tests were initiated by physicians?

\section{Methods}

We analyzed 2000 and 2015 National Health Interview Survey data. The overall National Health Interview Survey adult sample response rates were $72.1 \%$ (2000) and 55.2\% (2015). Our analyses included male respondents aged $\geq 40$ years who reported PSA testing as part of a routine examination in the past year and excluded men with PSA tests for other purposes or prostate cancer history. Our analyses included 1646 men from the year 2000 and 2024 men from 2015. We calculated age-standardized prevalence of PIPT for both years. For 2015, we used logistic regression to calculate adjusted prevalence ratios for PIPT. We also calculated the prevalence of ever discussing both advantages and disadvantages. We used SUDAAN 10 software (RTI International, Research Triangle Park, NC) to account for the sampling design.

\section{Results}

The age-standardized prevalence of PIPT was significantly higher in 2015 (84.9\%) than in 2000 $(72.3 \%)(P<.01)$. In 2015 , among men aged $\geq 70$ years who received a PSA screening test, nearly $90 \%$ reported that it was first suggested by a physician (Table 1). PIPT was positively associated with 2 or more comorbid conditions and number of patient visits to the doctor, but inversely associated with prostate cancer family history (data not shown). Up to one-third of men who were screened reported that they had ever participated in a discussion of advantages and disadvantages of PSA testing (Table 2); SDM was slightly higher with 
Table 2. Prevalence of Ever Discussed Both Advantages and Disadvantages of Prostate-Specific Antigen Testing Among Men Aged 40 Years and Older Who Had the Test Within the Past Year, National Health Interview Survey, 2015

\begin{tabular}{|c|c|c|c|c|}
\hline & \multicolumn{4}{|c|}{ Ever Discussed Advantages and Disadvantages* } \\
\hline & $\mathbf{N}^{+}$ & $\%$ & $95 \% \mathrm{CI}$ & $P$ value \\
\hline Total & 1955 & 31.0 & $28.1-34.1$ & \\
\hline Who first suggested the PSA test & & & & .061 \\
\hline Patient or someone else & 287 & 25.1 & $19.0-32.3$ & \\
\hline Physician & 1668 & 32.0 & $28.9-35.4$ & \\
\hline 40 to 54 years & 373 & 28.2 & $22.1-35.2$ & \\
\hline Who first suggested the PSA test & & & & .771 \\
\hline Patient or someone else & 74 & 26.2 & $14.6-42.5$ & \\
\hline Physician & 299 & 28.6 & $21.8-36.5$ & \\
\hline 55 to 69 years & 1003 & 34.8 & $30.8-39.1$ & \\
\hline Who first suggested the PSA test & & & & .006 \\
\hline Patient or someone else & 148 & 23.6 & $16.1-33.2$ & \\
\hline Physician & 855 & 36.8 & $32.4-41.3$ & \\
\hline $70+$ years & 579 & 26.0 & $21.8-30.6$ & \\
\hline Who first suggested the PSA test & & & & .830 \\
\hline Patient or someone else & 65 & 27.3 & $16.0-42.6$ & \\
\hline Physician & 514 & 25.8 & $21.3-30.8$ & \\
\hline
\end{tabular}

PSA, prostate-specific antigen testing; CI, confidential interval.

*Status of "Ever discussed advantages and disadvantages" was assessed based on two survey questions: (1) Did a doctor ever talk with you about the advantages of the test?; and (2) Did a doctor ever talk with you about the disadvantages of the test.

†Number may differ from the total of 2024 because of “don't know," refused, or missing responses.

PIPT (32\% vs $25 \%$ for initiation by the patient/ someone else), but not significantly so $(P=.06)$.

\section{Discussion}

In 2000 and 2015 , more than $70 \%$ of men who underwent PSA testing in the past year reported that their physicians were the first to suggest testing. Conflicting recommendations regarding PSA testing might have contributed to that high prevalence. ${ }^{1}$ Other factors might include physician beliefs about PSA screening effectiveness, perceived community standard of care, and malpractice concerns. ${ }^{2}$ Medicare reimbursement for annual PSA testing might contribute to the willingness of physicians to propose or support testing.

PIPT is positively associated with 2 or more comorbid conditions and the number of patient encounters with clinicians. More patient encounters may increase a clinician's opportunity to suggest the test. This study suggests that men with prostate cancer family history are more likely to first suggest PSA testing. In 2017, the US Preventive Task Force released draft recommendations, instead of against screening among men of all ages, calling for individualized decision making after discussion of potential benefits and harms of PSA testing among men aged 55 years to 69 years. ${ }^{3}$ In our study, more than two-thirds of men who were screened reported that they had never discussed advantages and disadvantages of PSA testing with physicians, a finding consistent with previous reports. $^{4,5}$ These results point to the challenges and needs in conducting SDM in clinical practice.

Limitations of our study include self-reported data (which may be less accurate than medical records), results that may not be representative of nonrespondents, and lack of details on the relationship to the patient when "someone else requested the test."

To see this article online, please go to: http://jabfm.org/content/ 31/4/658.full.

\section{References}

1. Berkowitz Z, Li J, Richards TB, Marcus PM. Patterns of prostate-specific antigen test use for prostate cancer screening in the United States, 2005-2015. Am J Prev Med 2017;53:909-913. 
2. Purvis Cooper C, Merritt TL, Ross LE, John LV, Jorgensen CM. To screen or not to screen, when clinical guidelines disagree: primary care physicians' use of the PSA test. Prev Med 2004;38:182-191.

3. Bibbins-Domingo K, Grossman DC, Curry SJ. The US Preventive Services Task Force 2017 draft recommendation statement on screening for prostate cancer: an invitation to review and comment. JAMA 2017;317:19491950.
4. Han PK, Kobrin S, Breen N, et al. National evidence on the use of shared decision making in prostate-specific antigen screening. Ann Fam Med 2013;11:306-14.

5. Li J, Berkowitz Z, Richards TB, Richardson LC. Shared decision making in prostate-specific antigen testing with men older than 70 years. J Am Board Fam Med 2013;26:401-8. 